\title{
Chromosome banding in the genus Pinus IV. Fluorescent banding patterns of chromosomes in eight taxa of haploxylone pines
}

\author{
Masahiro Hizume ${ }^{1,3}$, Kozue N. Ohtaka ${ }^{1}$, Kaoru M. Takeda ${ }^{1}$, Satomi Fujii ${ }^{1}$, \\ Yoko Yamasaki ${ }^{1}$ and Katsuhiko Kondo ${ }^{2}$ \\ ${ }^{1}$ Faculty of Education, Ehime University, 3 Bunkyo, Matsuyama, Ehime 790-8577, Japan; \\ ${ }^{2}$ Institute of Evolutionary Biology, 2-4-28 Kamiyouga, Setagaya-Ku, Tokyo 158-0098, Japan \\ ${ }^{3}$ Author for correspondence: (masahiro.hizume@ehime-u.ac.jp) \\ Received December 7, 2016; accepted December 22, 2016
}

\begin{abstract}
Somatic chromosomes of seven taxa of Asian haploxylon pines, Pinus armandii var. amamiana, P. armandii var. armandii, P. parviflora, $P$. pumila, $P . \mathrm{x}$ hakkodensis, $P$. koraiensis and $P$. bungeana, and a American species of $P$. edulis were observed by a fluorescent banding method using chromomycin $\mathrm{A}_{3}$ (CMA) and 4',6-diamidino-2-phenylindole (DAPI). The chromosome number of all taxa was $2 n=24$ and their karyotypes were composed of 22 long metacentric chromosomes and two short heterobrachial chromosomes as previous reports. CMA-bands appeared at the interstitial region and not at the proximal region of metacentric chromosomes. Interstitial CMA-bands were observed on 16-18 long metacentric chromosomes in chromosome complement of most species excepting for $P$. bungeana having six interstitial CMA-bands. The short chromosomes of most species have an interstitial CMA-band on their long arms and that of $P$. edulis had a proximal CMA-band. Clear proximal CMA- or DAPI-bands appeared in most species of subgenus Pinus were not observed in species of subgenus Strobus examined. DAPI-dots appeared at centromeric regions of all chromosomes and many thin DAPI-bands did at interstitial regions as appeared in the species of subgenus Pinus. The karyotype analysis combined with CMA- and DABI-bandings was useful for identification of each homologous chromosome and for chromosomal relationship among species in haploxylon pines.
\end{abstract}

KEYWORDS: Chromosome, Fluorescent banding, Haploxylone pine, Karyotype, Pinus, Strobus

The genus Pinus is the largest one composed of 120-126 species in Pinaceae (Shaw 1914; Critchfiled and Little 1966; Mirov 1967; Little and Critchfield 1969; Farjon 1984; Farjon and Styles 1997). They distribute widely in template to tropical climatic parts in north Hemisphere and one species, $P$. merksii expands over the equator at Sumatra Island, Indonesia (Critchfiled and Little 1966; Farjon 1984; Farjon and Styles 1997; Price et al. 1998). The Pinus shows a great diversity in structure, phenology, morphology, ecology, genecology, geography, genetics and molecular genetics. On the basis of pioneer works of Shaw (1914), Mirov (1967) and, Little and Critchfield (1969) their taxonomic treatments are used widely and, subgenera Pinus and Strobus are accepted. Several revisions have made adjustments to the species status and modified the taxonomic treatment at the ranks of subgenera, sections and/or subsections (Farjon 1984; Farjon and Styles 1997; Gernandt et al. 2003, 2005; Price et al. 1998; Liston et al. 1999; Syring et al. 2007; Hernández-León et al. 2013). In recent years molecular phylogenetic analyses using various DNA sequences of cytoplasmic and nuclear genomes were applied frequently to phylogenetic and taxonomic studies on Pinus species, and revealed reliable phylogenetic relationships among species. Then molecular phylogenetic trees constructed were compared with taxonomic treatments (Chaw et al. 1997; Liston et al. 1999; López et al. 2002; Zhang and Li 2004; Gernandt et al. 2005, 2009; Eckert and Hall 2006;
Tsutsui et al. 2009) and coincident with subgenera and sections. The subgenus Strobus has about 50 species and separated into two sections Strobus and Parrya by taxonomy and also molecular phylogeny (Zhang and $\mathrm{Li}$ 2004; Eckert and Hall 2006).

In a point of cytogenetic view the Pinus species is very conservative in a common chromosome number of $2 n=24$, has many long metacentric chromosomes forming a similar symmetric karyotype (Saylor 1972, 1983; Hizume 1988). Conserved karyotype is suitable for precise comparative karyotype analysis after an identification of each homoeologous chromosome and expected to supply valuable phylogenetic information. For chromosome identification of each homologous pair in chromosome complement, several techniques such as C-banding (Borzan and Papeš 1978; Tanaka and Hizume 1980; MacPherson and Filion 1981), G-banding (Drewry 1982), fluorescent banding (Hizume et al. 1983, 1989b, 1990; Jacobs et al. 2000; Islam-Faridi et al. 2007) and in situ hybridization (ISH) including fluorescent in situ hybridization (FISH) of rDNA probes (Hizume et al. 1992; Doudrick et al. 1995; Lubaretz et al. 1996; Jacobs et al. 2000; Liu et al. 2003; Cai et al. 2006; Islam-Faridi et al. 2007; Shibata et al. 2016) and, other probes such as PCSR and telomere sequences (Hizume et al. 2002b; Islam-Faridi et al. 2007; Shibata et al. 2016) were used for chromosome analysis in Pinus species. The fluorescent banding using CMA and DAPI displayed many 
Table 1. Locality or source of eight taxa of Pinus subgenus Strobus.

\begin{tabular}{|c|c|}
\hline Taxon & Locality (source) \\
\hline Pinus armandii Franch. var.armandii & $\begin{array}{l}\text { Liijan, Yunnan, Chine } \\
\text { Kunming, Yunnan, China }\end{array}$ \\
\hline P. armandii var. amamiana (koiz.) Hatsushima & Kumage, Kagoshima, Japan (FFPRI) \\
\hline P. parviflora Sieb \& Zucc. & $\begin{array}{l}\text { Fujiyoshida, Yamanashi, Japan (FFPRI) } \\
\text { Higashiakaisi, Ehime, Japan }\end{array}$ \\
\hline P. pumila (Pallas) Regel & Yatsugatake, Nagano, Japan (FFPRI) \\
\hline P. hakkodensis Makino & Ioudake, Aomori, Japan (FFPRI) \\
\hline P. koraiensis Sieb. \& Zucc. & Tohoku Brabch of FFPRI \\
\hline P. bungeana Zucc. Ex Endl. & Beijing, China \\
\hline P. edulis Engelm. & Coconia, Arizona, USA (U.S. For. Tree Seed Center, Georgia) \\
\hline
\end{tabular}

FFPRI: Seed Bank of Forestry and Forest Products Research Institute, Tsukuba.

fluorescent bands at interstitial and/or centromeric regions of most chromosomes in Pinus. Their band patterns were useful for chromosome identification and comparative karyotype analysis which revealed relationships among three Japanese species in subgenus Pinus (Hizume et al. 1983, 1989b, 1990). Recently the FISH with two or more probes was adapted to species of subgenera Pinus (Hizume et al. 2002b; Liu et al. 2003; Islam-Faridi et al. 2007; Shibata et al. 2016) and Strobus (Cai et al. 2006; Shibata et al. 2016). Shibata et al. (2016) showed a usefulness of multi FISH for chromosome identification and comparative karyotype analysis in many Pinus species. The multi FISH analysis seems the most excellent technique for comparative karyotype analysis but contains somewhat complex and difficult procedures, and high cost chemicals. The fluorescent banding using CMA and DAPI is very easy and highly reproducible procedure including just staining.

In this report the fluorescent banding patterns of chromosomes in eight taxa of Pinus subgenus Strobus were described to supply basic chromosomal information in the diversity of Pinus genome.

\section{Materials And Methods}

Seeds of seven taxa of Pinus subgenus Strobus were collected in natural forests and supplied from the resource centers showed in Table 1. Seeds were sowed on a filter paper wetted or sterilized sand in a pot and incubated. After two or more weeks of sowing primary roots of germinates were collected for chromosome observation and were prepared chromosome slides by a procedure of Hizu me $e t$ al. (1983). The chromosome preparations were stained sequentially with CMA and DAPI following a protocol of Kondo and Hizume (1982) and Hizume et al. (1983). The fluorescent banded chromosome images under an epi-florescence microscope were recorded on a high sensitive film.

\section{Results}

Eight Pinus taxa belonging to subgenus Strobus had $2 n=24$ chromosomes in somatic cells and the chromosome number confirmed a chromosome number of previous reports (Saylor 1983; Hizume 1988). Their karyotypes were composed of 11 pairs of long metacentric chromosomes of about ranging 15 to $12 \mu \mathrm{m}$ and one pair of short somewhat heterobrachial chromosomes (about $10 \mu \mathrm{m})$, which were also similar to previous reports of species of subgenus Strobus (Saylor 1983; Hizume 1988). Fluorescent band patterns with CMA and/or DAPI were described briefly below in each species of subgenus Strobus.

\section{Pinus armandii var. armandii and var. amamiana} CMA-bands appeared at the interstitial regions of one arm of 16-18 long metacentric chromosomes and not on six long metacentric chromosomes in a chromosome complement in both varieties (Figs.1A, 2). A pair of chromosomes had interstitial CMA-bands on their both chromosome arms. In var. amamiana had more two weak CMA-band at interstitial of two chromosomes. Two short submetacentric chromosomes had a CMA-band at the interstitial region of their long arm. Number of interstitial CMA-bands varied somewhat among seedlings (Table 2). In typical pattern four CMA-bands located at terminally interstitial regions, eight at the medium interstitial regions and six at the intermediate interstitial regions. One pair of long metacentric chromosomes has a CMA-band associating with thin CMA-band or CMA-dots. The location and size of CMA-bands was different among chromosome pairs and allowed identifying homologous chromosomes having CMA-band. In var. armandii, DAPI-banded chromosomes were observed (Fig. 1B). Many thin DAPI-bands appeared at the interstitial region of most chromosomes and DAPI-dots appeared at centromeric regions. Negative DAPI-bands were observed at interstitial CMA-band regions (Fig. 1). Combination of 

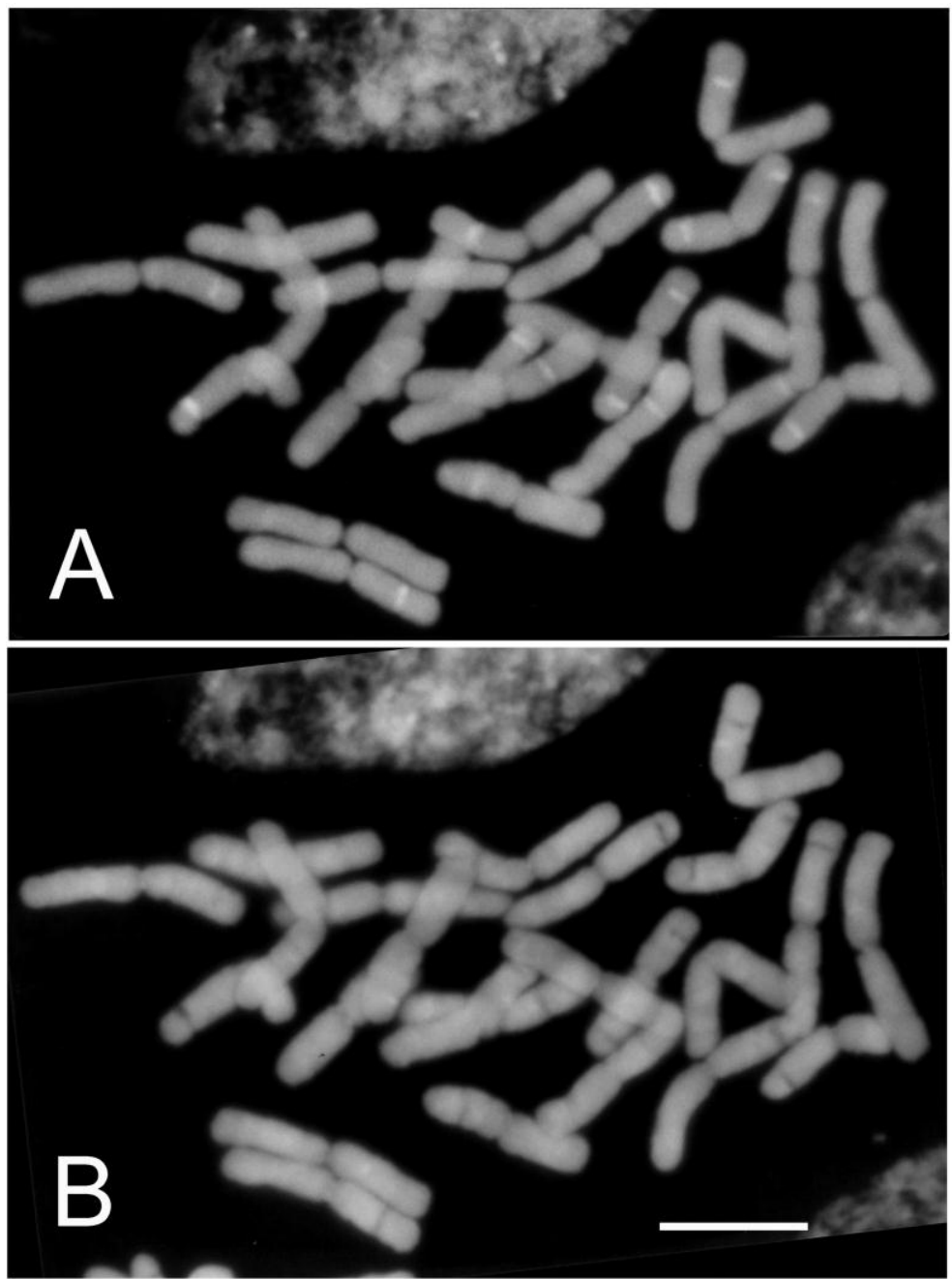

Fig. 1. Fluorescent banded chromosomes of P. armandii var. armandii. A: CMA banding, B: DAPI-banding. Bar $=10 \mu \mathrm{m}$.

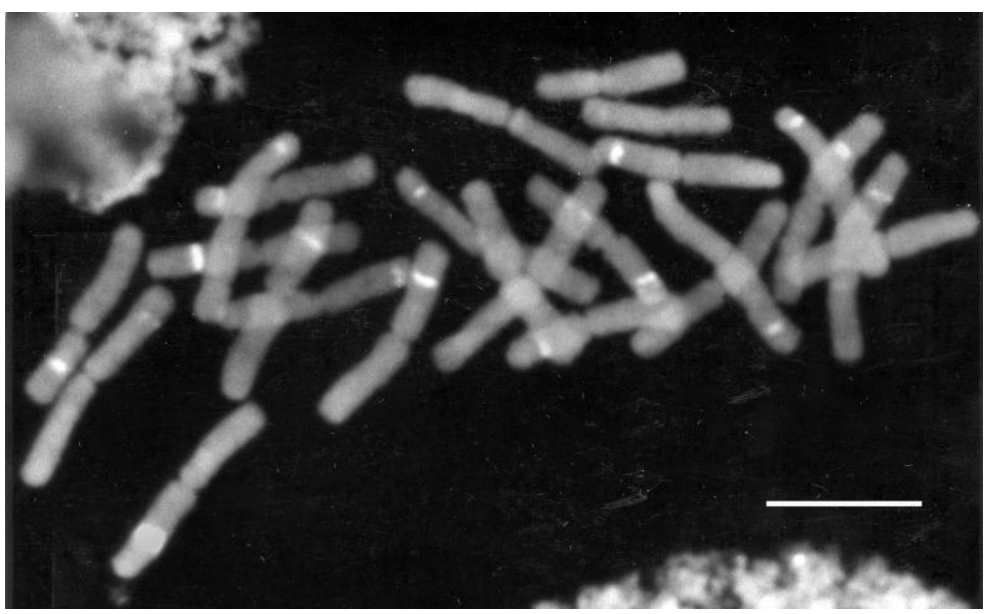

Fig. 2. Fluorescent banded chromosomes banded with CMA in P. armandii var. amamiana. Bar=10 $\mu \mathrm{m}$. 

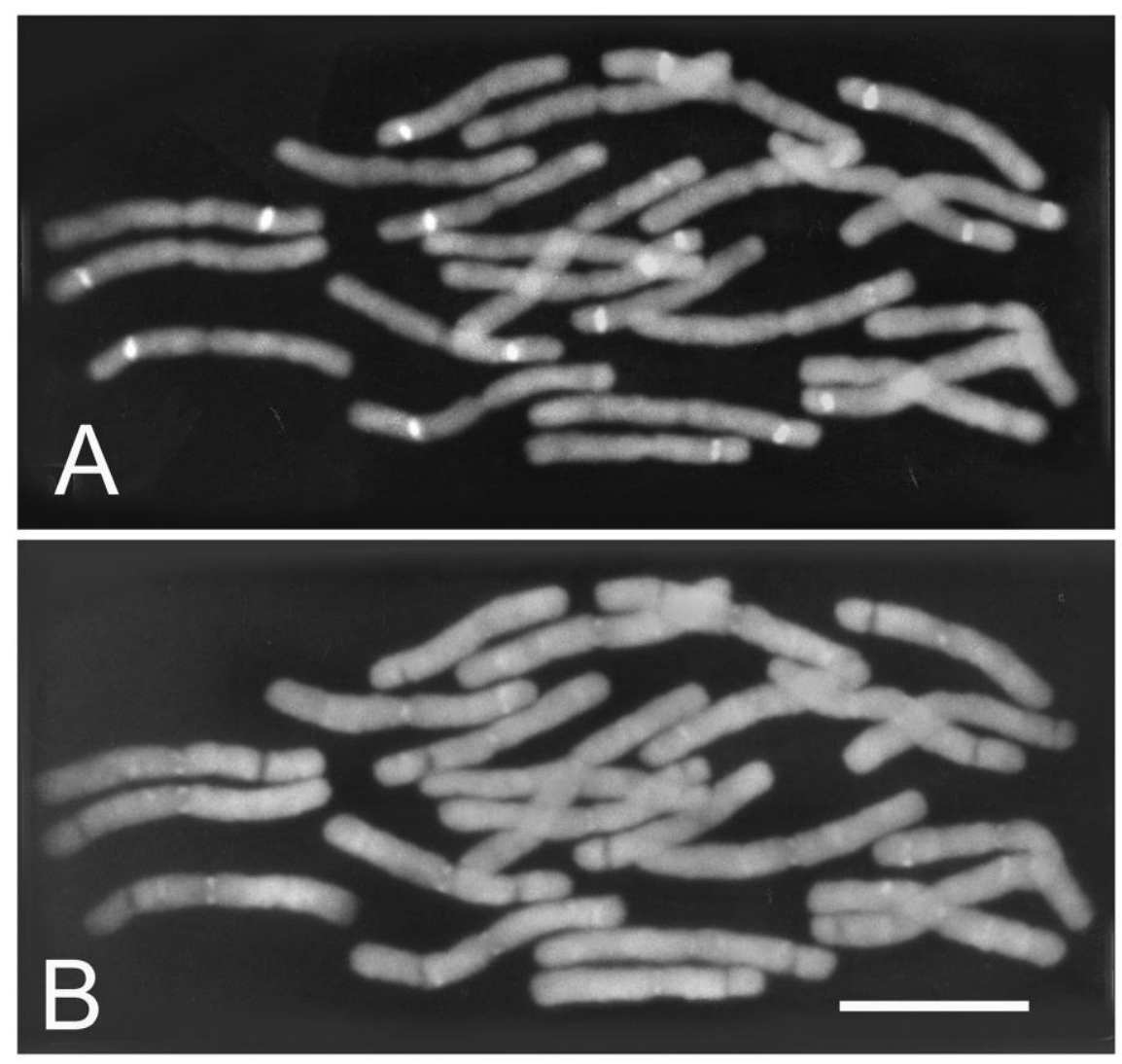

Fig. 3. Fluorescent banded chromosomes of P. parviflora. A: CMA banding, B: DAPI-banding. Bar=10 $\mu \mathrm{m}$

CMA- and DAPI-band patterns supplied useful information for exact chromosome identification.

\section{Pinus parviflora}

CMA-bands appeared on 16-18 long metacentric chromosomes and two short submetacentri c chromosomes (Fig. 3A). Sixteen interstitial CMA-bands of the long chromosomes were observed frequently among plants (Table 2). All CMA-bands appeared at the interstitial region of a single arm of each chromosome. The location of CMA-bands was at terminally or not proximally interstitial region. Short submetacentric chromosomes also had a CMA-band at the interstitial region of their long arm. All chromosomes had a pair of DAPI-dots at the centromeric regions (Fig. 3B). Several thin DAPI-bands also appeared at the interstitial regions of most long metacentric chromosomes. Chromosome regions of CMA-band were dark on bright chromosome arms with DAPI. Information combined of CMA- and DAPI-band patterns could identify each homologous chromosome in a chromosome complement.

\section{Pinus pumila}

CMA-bands appeared on 16-18 long metacentric chromosomes and two short submetacentric chromosomes
(Fig. 4). Four long metacentric chromosomes had interstitial CMA-bands at near chromosome end. One pair of long metacentric chromosomes carrying an interstitial CMA-band had thin CMA-band or pair CMA-dots appeared at closely distal side of thick CMA-band. Other interstitial CMA-bands also appeared at distal or near medium region and not at proximal region. Two small submetacentric chromosomes were located at the interstitial region of long arm as observed in the other species. On the basis of location of CMA-band and chromosome length most homologous chromosome pairs were identified.

\section{Pinus $\mathrm{x}$ hakkodensis}

Interstitial CMA-bands appeared on 16-18 long metacentric chromosomes and two short submetacentric chromosomes (Fig. 5). An intensity of fluorescence of CMA-band varied among chromosome pairs. The CMA-band of the small submetacentric chromosomes was located at the interstitial region of long arm as observed in P. parviflora and P. pumila. The CMA-band patterns of these three taxa are similar and seems support that this taxon is a hybrid species between $P$. parviflora and $P$. pumila. 


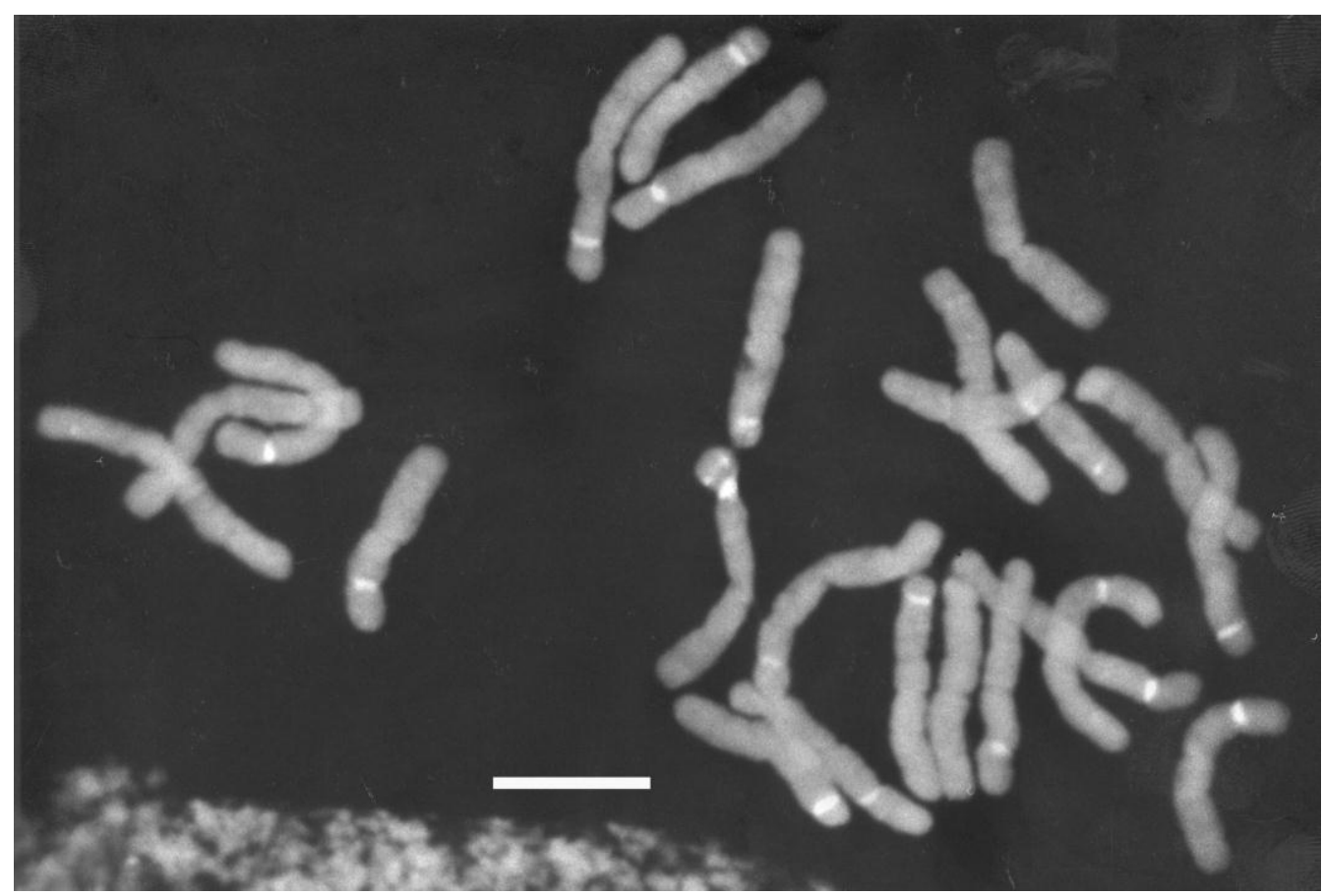

Fig. 4. Fluorescent banded chromosomes of P. pumila. A: CMA banding, B: DAPI-banding. Bar=10 $\mu \mathrm{m}$.

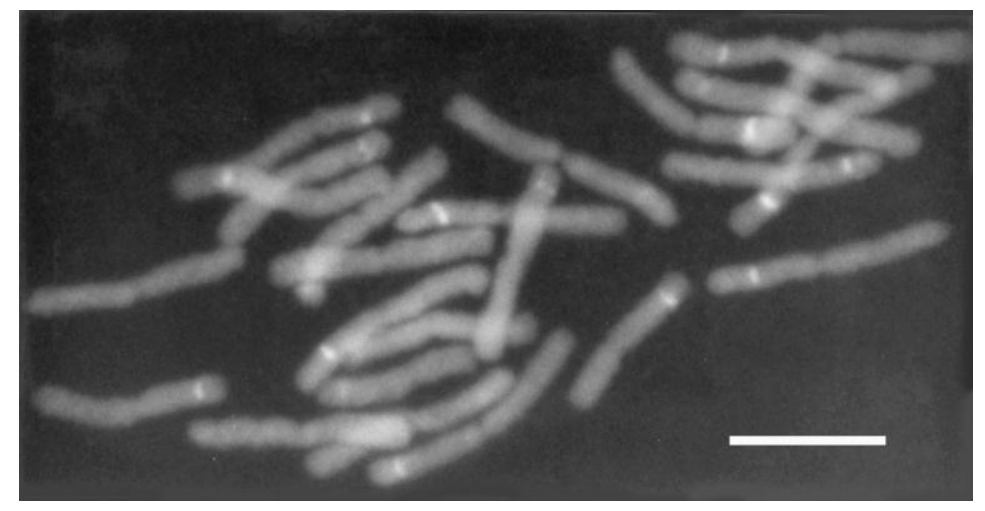

Fig. 5. Fluorescent banded chromosomes of $P . \times$ hakkodensis stained with CMA. Bar=10 $\mu$ m.

\section{Pinus koraiensis}

CMA-bands were observed at the interstitial regions of certain arms of 15-16 long metacentric chromosomes and at the interstitial regions of the long arms of the short submetacentric chromosomes (Fig. 6A). Four CMA-bands appeared at near terminal interstitial region than other CMA-bands. Other six chromosomes have no CMA-band. After DAPI-banding a pair of DAPI-dots appeared at centromeric regions of all chromosomes and thin DAPI-bands also appeared at the interstitial regions of most chromosomes (Fig. 6B). The fluorescent band patterns with thin DAPI-band and thick CMA-bands permits to identify nearly all homologous pairs in the chromosome complement.

\section{Pinus bungeana}

Four pairs of chromosomes had CMA-bands at the interstitial region. Four thick CMA-bands were located at interstitial region of one arm in long metacentric chromosomes and two did at interstitial region of short arm in the shortest chromosomes (Fig. 7A). Thin CMA-bands appeared at interstitial region of both arms in a pair of long metacentric chromosomes. Number of thick interstitial CMA-bands of this species is six that is less than other taxa of subgenera Strobus and Pinus examined. After DAPI-staining DAPI-dots appeared at the centromeric region of four chromosome pairs and did not clear in other chromosomes. Several clear interstitial DAPI-bands appeared on most chromosome arms (Fig. 7B). The regions 

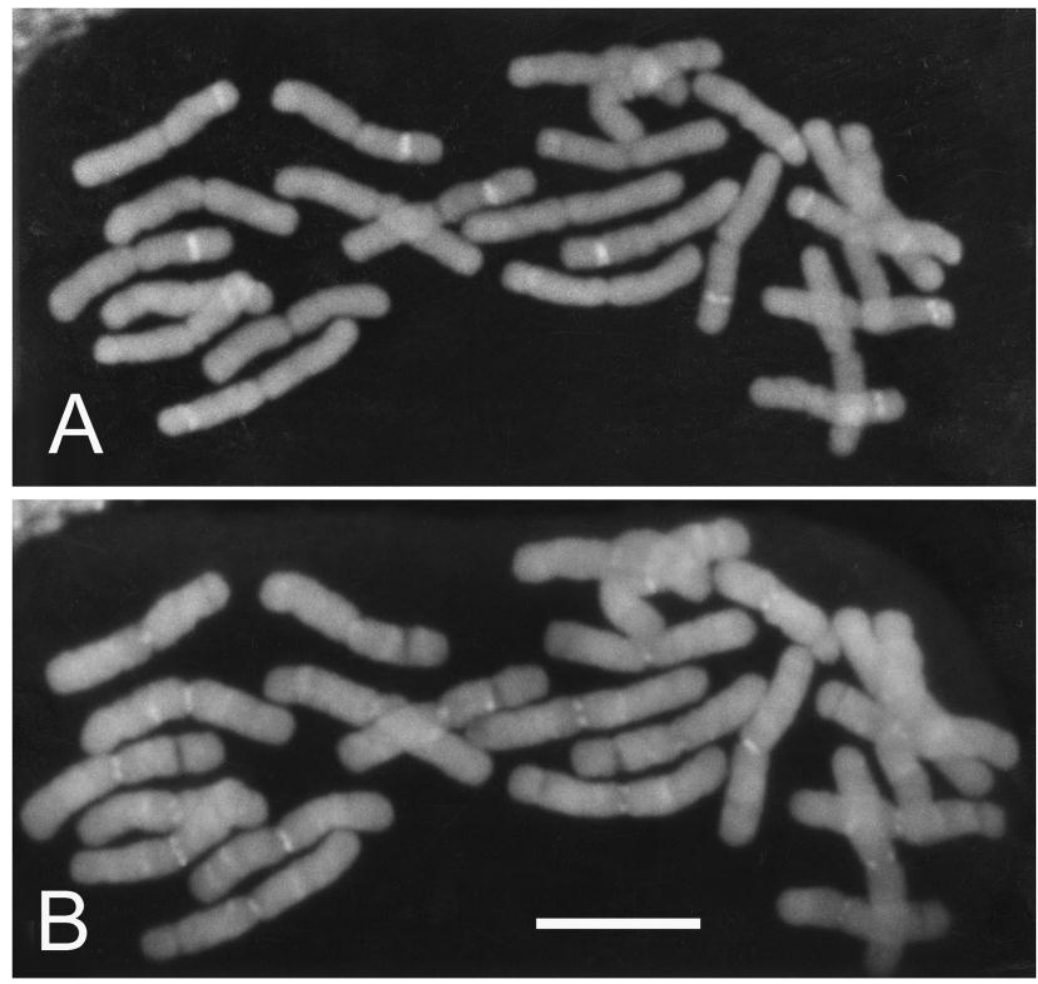

Fig. 6. Fluorescent banded chromosomes of P. koraiensis. A: CMA-banding, B: DAPI-banding. Bar=10 $\mu \mathrm{m}$.
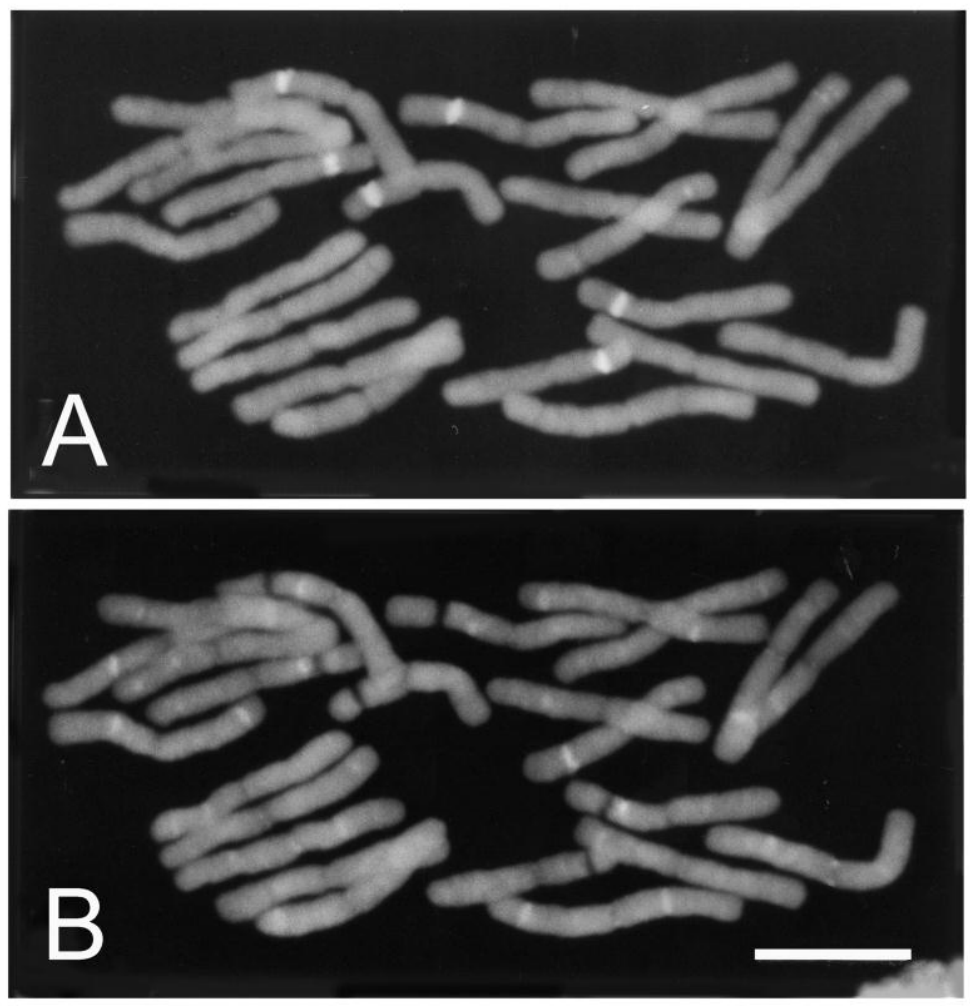

Fig. 7. Fluorescent banded chromosomes of P. bungeana. A: CMA banding, B: DAPI-banding. Bar=10 $\mu \mathrm{m}$. 

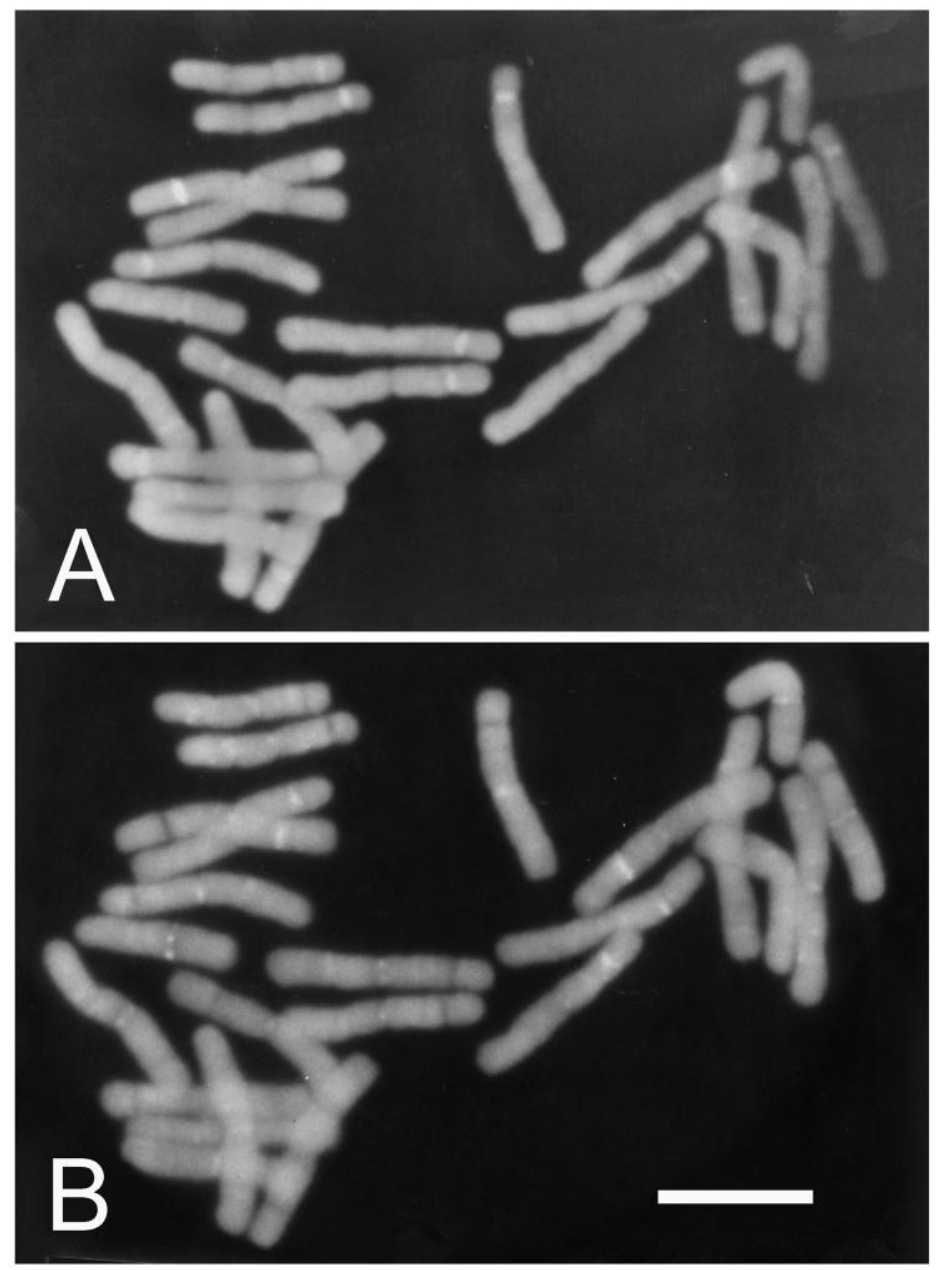

Fig. 8. Fluorescent banded chromosomes of P. edulis. A: CMA-banding, B: DAPI-banding. Bar=10 $\mu$ m.

of CMA-bands were observed negative one on the chromosome arms fluoresced with DAPI. The sites of clear DAPI-bands were also CMA-negative. These fluorescent banding patterns of CMA and DAPI, and morphology of chromosomes allowed identifying each homologous chromosome in a chromosome complement.

\section{Pinus edulis}

Above seven taxa are Asian species and P. edulis is one of American species. The CMA-bands appeared at the interstitial regions of 16-18 long metacentric chromosomes (Fig. 8A). In certain plants one or two long metacentric chromosomes had weak CMA-bands at the interstitial regions of both arms (Table 2). The number of chromosomes with no CMA-band was four to six. The short submetacentric chromosomes had a weak CMA-band at the proximal region. Pairs of DAPI-dots appeared at the centromeric regions of all chromosomes and many thin DAPI-bands appeared at the interstitial regions of most chromosomes (Fig. 8B). CMA- and DAPI-band patterns and chromosome morphology allowed identifying most homologous chromosome pairs in a chromosome complement.

\section{Discussion}

The CMA- and DAPI-band patterns of karyotype have been reported in many conifers of Pinaceae (Abies: Puizina et al. 2008, Hizume et al. 2016; Cedrus: Dagher-Kharrat et al. 2001; Keteleeria: Hizume et al. 1993b; Larix: Hizume et al. 1988c, 1993a; Picea: Hizume et al. 1989a, Hizume and Kuzukawa 1995, Lubaretz et al. 1996, Siljak-Yakovlev et al. 2002; Pinus: Hizume et al. 1983, 1989b, 1990, Doudrick et al. 1995; Pseudolarix: Hizume 2015b; Pseudotsuga: Hizume and Kondo 1992, Hizume and Akiyama 1992; Tsuga: Hizume 2015a), Cupressaceae (Kondo and Hizume 1982; Hizume et al. 1988a; Hizume and Fujiwara 2016), Podocarpaceae (Hizume et al. 1988b; Davis et al. 1997), and Araurariaceae (Hizume and Kan 2016). In common with angiosperm species some thick CMA-bands appear at the secondary constrictions in all conifer species investigated. Feature of DAPI-band pattern varied depending on genera. 
Table 2. Number of plants and number of chromosome with various CMA-band type in eight taxa of Pinus subgenus Strobus.

\begin{tabular}{|c|c|c|c|c|c|c|c|c|c|}
\hline \multirow{2}{*}{$\begin{array}{c}\text { Taxon of subsenus } \\
\text { Strobus }\end{array}$} & \multirow{2}{*}{$\begin{array}{l}\text { No. of } \\
\text { plants }\end{array}$} & \multicolumn{8}{|c|}{ Number of chormosomes after CMA-banding } \\
\hline & & $\mathrm{mI}$ & $\mathrm{mII}$ & $\mathrm{mCI}$ & $\mathrm{mC}$ & m- & $\mathrm{smI}$ & $\mathrm{smC}$ & sm- \\
\hline \multirow{3}{*}{$\begin{array}{l}\text { P. armandii } \\
\text { var. armandii }\end{array}$} & 7 & 14 & 2 & 0 & 0 & 6 & 2 & 0 & 0 \\
\hline & 1 & 14 & 2 & 0 & 0 & 5 & 2 & 0 & 0 \\
\hline & 3 & 14 & 2 & 0 & 0 & 4 & 2 & 0 & 0 \\
\hline \multirow{3}{*}{$\begin{array}{l}\text { P. armandii } \\
\text { var. amamiana }\end{array}$} & 2 & 15 & 1 & 0 & 0 & 6 & 2 & 0 & 0 \\
\hline & 1 & 16 & 0 & 0 & 0 & 6 & 2 & 0 & 0 \\
\hline & 3 & 18 & 0 & 0 & 0 & 4 & 2 & 0 & 0 \\
\hline \multirow[t]{3}{*}{ P. parviflora } & 12 & 16 & 0 & 0 & 0 & 6 & 2 & 0 & 0 \\
\hline & 4 & 17 & 0 & 0 & 0 & 5 & 2 & 0 & 0 \\
\hline & 4 & 18 & 0 & 0 & 0 & 4 & 2 & 0 & 0 \\
\hline \multirow[t]{3}{*}{ P. pumila } & 3 & 16 & 0 & 0 & 0 & 6 & 2 & 0 & 0 \\
\hline & 1 & 17 & 0 & 0 & 0 & 5 & 2 & 0 & 0 \\
\hline & 1 & 18 & 0 & 0 & 0 & 4 & 2 & 0 & 0 \\
\hline P. hakkodensis & 5 & 18 & 0 & 0 & 0 & 4 & 2 & 0 & 0 \\
\hline \multirow[t]{2}{*}{ P. koraiensis } & 1 & 15 & 0 & 0 & 0 & 7 & 2 & 0 & 0 \\
\hline & 14 & 16 & 0 & 0 & 0 & 6 & 2 & 0 & 0 \\
\hline P. bungeana & 8 & 4 & 2 & 0 & 0 & 16 & 2 & 0 & 0 \\
\hline \multirow[t]{7}{*}{ P. edulis } & 1 & 15 & 2 & 0 & 0 & 5 & 0 & 2 & 0 \\
\hline & 2 & 16 & 0 & 0 & 0 & 6 & 0 & 2 & 0 \\
\hline & 6 & 16 & 1 & 0 & 0 & 5 & 0 & 2 & 0 \\
\hline & 1 & 16 & 2 & 0 & 0 & 4 & 0 & 2 & 0 \\
\hline & 3 & 17 & 0 & 0 & 0 & 5 & 0 & 2 & 0 \\
\hline & 1 & 17 & 1 & 0 & 0 & 4 & 0 & 2 & 0 \\
\hline & 3 & 18 & 0 & 0 & 0 & 4 & 0 & 2 & 0 \\
\hline
\end{tabular}

Symbols show m: long metacentric chromosomes, sm: shortest chromosomes.

CMA-band types are ecpressed in C: centromeric CMA-band, I: interstitial CMA-babnd,

II: interstitial CMA-bands on both arm, -: no CMA-band.

In Pinus and Larix the fluorescent banding pattern supplied valuable information for chromosomal relationships among species.

In four diploxylon species of Pinus (Hizume et al. $1983,1989 b, 1990)$ the fluorescent band pattern is useful for an identification of homologous chromosomes in each chromosome complement and for reveal of interspecific relationships of chromosomes among species. Many CMA-bands appeared at the interstitial and/or centromeric regions of most chromosomes. DAPI-bands appear at the proximal region of some chromosomes and many thin DAPI-bands at the interstitial region of most chromosomes. A pair of DAPI-dots appeared at the centromeric region of each chromosome. Comparison of fluorescent band patterns among these Pinus species showed an obvious difference in fluorescent bands of proximal region. The four species investigated belonging to subgenus Pinus have thick CMA- or DAPI-band at the proximal region of most chromosomes, but the species of subgenus Strobus examined this time have no proximal thick band. This point seems an exact difference between subgenus Pinus and Strobus. There is similarity in presence of interstitial thick CMA-bands, interstitial thin DAPI-bands, and centromeric DAPI-dots between subgenera.

In subgenus Strobus seven taxa had 16-18 interstitial CMA-bands in each chromosome complement and $P$. bungeana showed less number of six interstitial CMA-bands (Table 2). This difference might coincident with position of phylogenetic trees of subgenus Strobus (Eckert and Hall 2006; Wang and Wang 2014) and it needs to analyze the fluorescent banding in more species of this subgenus to confirm a phylogenetic importance of number of interstitial CMA-bands. The American species, $P$. edulis showed a proximal CMA-band on the short submetacentric chromosomes. This character should be also confirmed by a survey in other American species of this subgenus.

Molecular cytogenetic studies have performed in seven species of subgenus Strobus (Cai et al. 2006; Shibata et al. 2016). All interstitial FISH signals of $45 \mathrm{~S}$ rDNA probe seems correspond to thick CMA-bands as reported in subgenus Pinus (Hizume et al. 1992, 2001, 2002b) and Strobus (Cai et al. 2006; Shibata et al. 2016). 
In seven species of subgenus Strobus FISH signals of $5 \mathrm{~S}$ rDNA appeared in the close distal side of $45 \mathrm{~S}$ rDNA signal at the terminally interstitial region of chromosomes. The closely associated $45 \mathrm{~S}$ and $5 \mathrm{~S}$ rDNA signals seems that close double CMA-bands containing each $45 \mathrm{~S}$ and $5 \mathrm{~S}$ rDNA were observed sometimes on not-well condensed chromosome preparation (Fig. 4). 5S rDNA loci appear on CMA-band in other conifers (Hizume and Kuzukawa 1995; Hizume et al. 1996; Vischi et al. 2003; Shibata et al. 2004; Shibata and Hizume 2008). In all the species of subgenus Pinus examined, several chromosomes had proximal FISH signals of PCSR but the species of subgenus Strobus had not at all (Shibata et al. 2016). This phenomenon corresponds to an absence of a thick fluorescent band at proximal region of any chromosome in the subgenus Strobus.

In the species of subgenera Pinus (Hizume et al. 1983, 1989b, 1990) and Strobus (Figs. 2, 5-7) examined many interstitial DAPI-bands appeared commonly on their chromosome arms. As DAPI binds preferentially AT-base pairs of DNA sequence bright DAPI-bands indicate that certain AT-rich sequences are localized in the DAPI-band region. In species of subgenus Pinus the FISH using a probe of telomere sequence showed many interstitial signals on thin DAPI-bands in most chromosomes (Hizume et al. 2002b; Islam-Faridi et al. 2007; Shibata et al. 2016) but did not appear at any chromosomes in two species of subgenus Strobus (Shibata et al. 2016). The phenomenon indicates that AT-rich DNA sequences localizing in the interstitial DAPI-bands in genus Pinus are different between subgenera. It is desired an isolation of AT-rich sequence locating at an interstitial DAPI-band of subgenus Strobus species and application as a probe for FISH. The centromeric DAPI-dots in all chromosomes of both subgenera are expected to contain unknown common DNA sequence in Pinus. When the DNA sequence locating at DAPI-dots is identified, the centromeric sequence will be important for understanding of Pinus or conifer chromosome structure.

In taxonomic system of Pinus the subgenus Strobus is divided into two sections Strobus and Parrya and, each section dose into two and five subsections, respectively (Farjon and Styles 1997; Gernandt et al. 2003, 2005; Price et al. 1998). Molecular phylogenetic studies were performed using ITS sequence (Liston et al. 1999) and chloroplast DNA sequences (Eckert and Hall 2006), and supported the sections and some subsections. Below is a correspondence between species investigated and subdivisions of subgenus Strobus.

Section Strobus

subsection Cembrea----- P. koraiensis, P. pumila

subsection Strobi ----- P. armandii, P. parviflora

Section Parrya

subsection Cembroides----- P. edulis

subsection Gerardianea----- P. bungeana

The band pattern in number and location of CMA-bands (Table 2) is similar among species of section
Strobus examined excepting for $P$. bungeana showing small number of interstitial CMA-bands. The short chromosomes of most species had interstitial CMA-band on long arm but only $P$. edulis have a proximal CMAband. The two species were put in section Parrya and belonged to different subsections. The fluorescent banded karyotypes suggest that the taxa in section Parrya might show higher diversity than other section Strobus. Our observation on fluorescent chromosome banding was achieved on only eight taxa out of about 50 species in subgenus Strobus. When fluorescent banded karyotypes are carefully observed in more species and compared with reliable molecular phylogenetic relationship, the chromosomal relationships among the species or a feature of chromosomes in phylogenetic diversity of subgenus Strobus will be revealed.

ACKNOWLEDGMENTS We express sincerely thanks several collaborators for collecting and supplying pine seeds examined.

\section{Literature Cited}

Borzan, Z. and Papeš, D. 1978. Karyotype analysis in Pinus: A contribution to the standardization of the karyotype analysis and review of some applied techniques. Silvae Genet. 27:144-150.

Cai, Q., Zhang, D., Liu, Z. L. and Wang, X. R. 2006. Chromosomal localization of 5S and 18S rDNA in five species of subgenus Strobus and their implications for genome evolution of Pinus. Ann. Bot. 97:715-722.

Chaw, S. M., Zharkikh, A., Sung, H. M., Lau, T. C. and Li, W. H. 1997. Molecular phylogeny of extant gymnosperms and seed plant evolution: analysis of nuclear 18S rRNA sequences. Mol. Biol. Evol. 14:56-68.

Critchfiled, W. B. and Little, E. L. 1966. Geographic distribution of the pines of the world. US Dept. Agr. For. Serv. No. 991: 1-97.

Dagher-Kharrat, M. B., Grenier, G., Bariteau, M., Brown, S., Siljak-Yakovlev, S. and Savouré, A. 2001. Karyotype analysis reveals interspecific differentiation in the genus Cedrus despite genome size and base composition constancy. Theor. Appl. Genet. 103:846-854

Davies, B. J., O'brien, I. E. W. and Murray, B. G. 1997. Karyotypes, chromosome bands and genome size variation in New Zealand endemic gymnosperms. Plant Syst. Evol. 208:169-185.

Doudrick, R. L., Heslop-Harrison, J. S., Nelson, C. D., Schmidt, T., Nance, W. L. and Schwarzacher, T. 1995. Karyotype of slash pine (Pinus elliottii var. elliottii) using patterns of fluorescence in situ hybridization and fluorochrome banding. J. Hered. 86: 289-296.

Drewry, A. 1982. G-banded chromosomes in Pinus resinosa. J. Hered.73: 305-306.

Eckert, A. J. and Hall, B. D. 2006. Phylogeny, historical biogeography, and patterns of diversification for Pinus (Pinaceae): Phylogenetic tests of fossil-based hypotheses. Mol. Phylogenet. Evol. 40:166-182

Farjon, A. 1984. Pines: Drawings and Descriptions of the Genus Pinus. EJ Brill, Leiden. 
Farjon, A. and Styles, B. T. 1997. Pinus (Pinaceae). New York Bot.Gard., New York.

Gernandt, D. S., Liston, A. and Piñero, D. 2003. Phylogenetics of Pinus subsections Cembroides and Nelsoniae inferred from cpDNA sequences. Syst. Bot. 28:657-673.

Gernandt, D. S., Hernández-León, S., Salgado-Hernández, E. and Pérez de La Rosa, J. A. 2009. Phylogenetic relationships of Pinus subsection Ponderosae inferred from rapidly evolving cpDNA regions. Syst. Bot. 34:481-491.

Gernandt, D. S., López, G. G., García, S. O. and Liston, A. 2005. Phylogeny and classification of Pinus. Taxon 54: 29-42.

Hernández-León, S., Gernandt, D. S., de la Rosa, J. A. P. and Jardón-Barbolla, L. 2013. Phylogenetic relationships and species delimitation in Pinus section Trifoliae inferred from plastid DNA. PloS one 8: e70501.

Hizume, M. 1988. Karyomorphological studies in the family Pinaceae. Mem. Ehime Univ. Fac. Edu., Ser. 3 8: p1-108.

Hizume, M. 2015a. Fluorescent banding pattern in chromosomes of Tsuga forrestii and T. sieboldii, Pinaceae. Chromosome Bot. 9:95-100.

Hizume, M. 2015b. Fluorescent band pattern of chromosomes in Pseudolarix amabilis, Pinaceae. Cytologia 80:151-157.

Hizume, M. and Akiyama, M. 1992. Size variation of chromomycin $\mathrm{A}_{3}$-band in chromosomes of Douglas fir, Pseudotsuga menziesii. Jpn. J. Genet. 67: 425-435.

Hizume, M. and Fujiwara, M. 2016. Fluorescent chromosome banding patterns of several species in the Cupressaceae sensu stricto. Chromosome Bot. 11:1-8.

Hizume, M. and Kan, M. 2015 Fluorescent banding pattern of chromosomes in Araucaria araucana, Araucariaceae. Cytologia 80: 399-403.

Hizume, M. and Kondo, K. 1992. Fluorescent chromosome banding in five taxa of Pseudotsuga, Pinaceae. Kromosomo II-66: 2257-2268.

Hizume, M. and Kuzukawa, Y. 1995. Chromosome banding in Picea. II. Relationships between rDNA loci and chromomycin $\mathrm{A}_{3}$-bands in somatic chromosomes of $P$. jezoensis var. hondoensis. Kromosomo II-79-80:2754-2759.

Hizume, M., Ohgiku, A. and Tanaka, A. 1983. Chromosome banding in the genus Pinus I. Identification of chromosomes in P. nigra by fluorescent banding method. Bot. Mag. Tokyo 96: 273-276.

Hizume M., Abe K. K. and Tanaka A. 1988a. Fluorescent chromosome bandings in Taxodiaceae. Kromosomo II-50:1609-1627.

Hizume, M., Shiraishi, H. and Tanaka, A. 1988b. A cytological study of Podocarpus macrophyllus with special reference to sex chromosomes. Jpn. J. Genet. 63: 413-423.

Hizume, M., Tominaga, K. and Tanaka, A. 1988c. Fluorescent chromosome banding in Larix leptolepis (Pinaceae). Bot. Mag. Tokyo 101: 333-336.

Hizume, M., Kishimoto, K., Kubo, Y. and Tanaka, A. 1989a. Fluorescent chromosome banding in Picea. I. Difference in chromomycin $\mathrm{A}_{3}$ band pattern between $P$. jezoensis var. jezoensis and P. jezoensis var. hondoensis. Kromosomo II -53: 1736-1744.

Hizume, M., Ohgiku, A. and Tanaka, A. 1989b. Chromosome banding in the genus Pinus II. Interspecific variation of fluorescent banding patterns in $P$. densiflora and $P$. thubergii. Bot. Mag. Tokyo 102: 25-36.

Hizume, M., Arai, M. and Tanaka, A. 1990. Chromosome banding in the genus Pinus III. Fluorescent banding pattern of $P$. luchuensis and its relationships among the Japanese diploxylon pines. Bot. Mag. Tokyo 103:103-111.

Hizume, M., Ishida, F. and Murata, M. 1992. Multiple locations of ribosomal RNA genes in chromosomes of pines, Pinus densiflora and $P$. thunbergii. Jpn. J. Genet. 67:389-396.

Hizume, M., Tominaga, H. H., Kondo, K., Gu, Z. and Yue, Z. 1993a. Fluorescent chromosome banding in six taxa of Eurasian Larix, Pinaceae. Kromosomo II-69:2342-2354.

Hizume, M., Fujii, S., Kondo, K., Gu, Z. and Yue, Z. 1993 b. Fluorescent bandings in Ketelerria evelyniana and $K$. davidiana var. formosana, Pinaceae. Kromosomo II-71-72:2443-2450.

Hizume, M., Kuzukawa, Y. and Kondo, T. 1996. Physical mapping of 5S rDNA on chromosomes in Pseudotsuga menziesii, Pinaceae. Kromosomo II 83-84: 2893-2900.

Hizume, M., Shibata, F., Maruyama, Y. and Kondo, T. 2001. Cloning of DNA sequences localized on proximal fluorescent chromosome bands by microdissection in Pinus densiflora Sieb. \& Zucc. Chromosoma 110:345-351.

Hizume, M., Shibata, F., Matsusaki, Y. and Garajova, Z. 2002b. Chromosome identification and comparative karyotypic analyses of four Pinus species. Theor. Appl. Genet. 105: 491-497.

Hizume, N., Yamasaki, Y. and Kan, M. 2016. Fluorescent chromosome banding patterns in six species of Abies, Pinaceae. Cytologia 81:61-67.

Islam-Faridi, M. N., Nelson, C. D. and Kubisiak, T. L. 2007. Reference karyotype and cytomolecular map for loblolly pine (Pinus taeda L.). Genome 50: 241-251.

Jacobs, M. D., Gardner, R. C. and Murray, B. G. 2000. Cytological characterization of heterochromatin and rDNA in Pinus radiata and P. taeda. Plant Syst. Evol. 223: 71-79.

Kondo, T. and Hizume, M. 1982. Banding for the chromosomes of Cryptomeria japonica D. Don. J. Jpn. For. Soc. 64: 356-358.

Liston, A., Robinson, W. A., Piñero, D. and Alvarez-Buylla, E. R. 1999. Phylogenetics of Pinus (Pinaceae) based on nuclear ribosomal DNA internal transcribed spacer region sequences. Mol. Phylogenet. Evol. 11: 95-109.

Little, E. L. and Critchfield, W. B. 1969. Subdivision of the Genus Pinus (Pines). USA Depart. Agr. For. Serv., Washington, D.C.

Liu, Z. L., Zhang, D., Hong, D. Y. and Wang, X. R. 2003. Chromosomal localization of 5S and 18S-5.8S-25S ribosomal DNA sites in five Asian pines using fluorescence in situ hybridization. Theor. Appl. Genet. 106:198-204.

López, G. G., Kamiya, K. and Harada, K. 2002. Phylogenetic relationships of diploxylon pines (subgenus Pinus) based on plastid sequence data. Inter. J. Plant Sci. 163:737-747.

Lubaretz, O., Fuchs, J., Ahne, R., Meister, A. and Schubert, I. 1996. Karyotyping of three pinaceae species via fluorescent in situ hybridization and computer-aided chromosome analysis. Theor. Appl. Genet. 92:411-416.

MacPherson, P. and Filion, W. G. 1981. Karyotype analysis and the distribution of constitutive heterochromatin in five species of Pinus. J. Hered. 72:193-198. 
Mirov, N. T. 1967. The Genus Pinus. Ronald Press Co., New York.

Puizina, J., Sviben, T., Krajacic-Sokol, I., Zoldoš-Pećnik, V., Siljak-Yakovlev, S., Papeš, D. and Besendorfer, V. 2008. Cytogenetic and molecular characterization of the Abies alba genome and its relationship with other members of the Pinaceae. Plant Biol. 10: 256-267.

Price, R. A., Liston, A. and Strauss, S. H., 1998. Phylogeny and systematics of Pinus. In: Richardson, D. M. (Ed.), Ecology and Biogeography of Pinus. Cambridge Univ. Press, Cambridge, pp. 49-68.

Saylor, L. C. 1972. Karyotype analysis of the genus Pinus-subgenus Pinus. Silvae Genet. 21: 155-163.

Saylor, L. C. 1983. Karyotype analysis of the genus Pinus-subgenus Strobus. Silvae Genet. 32:119-124.

Shaw, G. R. 1914. The genus Pinus. Publ. Arnold Arbor. 5:1-96.

Shibata, F. and Hizume, M. 2008. Comparative FISH karyotype analysis of 11 Picea species. Cytologia 73:203-211.

Shibata, F., Hizume, M. and Garajova, Z. 2004. Conserved FISH karyotypes in four species of Abies (Pinaceae). Chromosome Sci. 8: 95-98.

Shibata, F., Matsusaki, Y. and Hizume, M. 2016. A comparative analysis of multi-probe fluorescence in situ hybridisation (FISH) karyotypes in 26 Pinus species (Pinaceae). Cytologia 81:409-421.
Siljak-Yakovlev, S., Cerbah, M., Coulaud, J., Stoian, V., Brown, S. C., Zoldos, V., Jelenic, S. and Papes, D. 2002. Nuclear DNA content, base composition, heterochromatin and rDNA in Picea omorika and Picea abies. Theor. Appl. Genet. 104:505-512.

Syring, J., Farrell, K., Businský, R., Cronn, R. and Liston, A. 2007. Widespread genealogical nonmonophyly in species of Pinus subgenus Strobus. Syst. Biol. 56: 163-181.

Tanaka, R. and Hizume, M. 1980. C-banding treatment for the chromosomes of some gymnosperms. Bot. Mag. Tokyo 93: 167-170.

Tsutsui, K., Suwa, A., Sawada, K. I., Kato, T., Ohsawa, T. A. and Watano, Y. 2009. Incongruence among mitochondrial, chloroplast and nuclear gene trees in Pinus subgenus Strobus (Pinaceae). J. Plant Res. 122: 509-521.

Vischi, M., Jurman, I., Bianchi, G. and Morgante, M. 2003. Karyotype of Norway spruce by multicolor FISH. Theor. Appl. Genet.107: 591-597

Wang, B. and Wang, X. R. 2014. Mitochondrial DNA capture and divergence in Pinus provide new insights into the evolution of the genus. Mol. Phylogenet. Evol. 80: 20-30.

Zhang, Z. Y. and Li, D. Z. 2004. Molecular phylogeny of section Parrya of Pinus (Pinaceae) based on chloroplast matK gene sequence data. Acta Bot. Scinica 46: 171-179. 